\title{
Forming Estimation Cluster Structures from the Point of View of Competitiveness of Potential of Republic Mary El with the Influence of Economic Sanctions of the West
}

\author{
Svetlana G. Kreneva \\ Elena N. Halturina \\ IInar M. Nurmuhametov \\ Tatyana B. Bakhtina \\ Mari state university, Yoshkar-Ola, Russia \\ Email:kreneva.sv@yandex.ru
}

\section{Doi:10.5901/mjss.2015.v6n3s7p245}

\begin{abstract}
Now in any social - economic system including in Mary El Republic, the concept of economic development and competitiveness is actual. Quantity and quality growth of clusters in republic is confirmed with viability of the given model of development of business and territory. The cluster approach in system gives a number of advantages (institutional, innovative, increase of efficiency of production activity) for which account probably to achieve increase in economic growth, change of structural shifts of region, increase in volume of involved direct investments, employment solutions of a problem. Effective realisation of cluster structure demands creation of adequate system of monitoring and a realisation estimation of cluster initiatives. Their continuity should be an important condition of functioning of systems of monitoring, i.e. possibility in real time to trace growth and the barriers interfering development of clusters. It is obvious that cluster structures can be formed both within the limits of one industry, and between industries. Availability of close interrelations between region industries - buyers and manufacturers of goods - testifies to communication of the enterprises of the given industries on a chain of creation of value added and reflects possibility synergetic effect at deepening and expansion of their partner relations. Thus, the close connection between industries pledges conditions for forming cluster structures in increase of competitiveness of potential of region.
\end{abstract}

Keywords: cluster, cluster structure, territorial integration, competitiveness, potential.

\section{Introduction}

One of the main problems of forming of clusters in Mary El Republic consists in necessity of belief for a positive effect from clusterization of participants of business processes which do not accept innovations and are not inclined to risk, participating in interfirm cooperation. Another important problems complicating forming innovative cluster are backwardness of small and average business, and also weakness of tripartite communications between the basic subjects of innovative process (a science, business and the state). In our country, as it is known, the science and business practically do not co-operate with each other, or these communications are too weak, preferring to be guided by the state help separately. Besides, still there is no accurate determination of concept cluster as economic category that in some cases leads to mess, and objects absolutely different in the genesis (for example, territorial and production complexes) are referred to as clusters that is not admissible from the point of view of efficiency of development of any system.

The major task on an expansion way of cluster initiatives in Republic Mari El is creation of effective is standardlegal (legislative) base without which it is impossible to work correctly a legal component of forming and effective functioning cluster structures. Also it would be reasonable to develop general methodology regarding forming and functioning clusters and support mechanisms of cluster initiatives of concrete social and economic territory (Malitskaya \& Volkov, 2012)

Clusters are the structures, formed independently, instead of it is artificial authorities. In case of compulsory forming of clusters in region economy there are prototypes of territorial and production complexes that is not the effective factor of their development and transformation. In determination of the sizes of the enterprises which are participants clusters two opposite cases are possible. The first case represents group economically co-operating small and medium scale enterprises with poorly expressed uniform centre and competing among themselves. It is regional cluster, i.e. the 
spatial grouping of the similar and connected economic activities forming a basis of the local environment, promoting modulations of knowledge and stimulating various modes of study and adaptations. Such clusters is usual consist from small both medium scale enterprises, and the basic element of their success is concentrated in forces of the social capital and geographical (territorial) affinity. Their other feature consists that the small or average subject of business are less interconnected, than in large industrial clusters (Skubko, 2010).

The second case is connected with forming of cluster large enterprises with accurately expressed uniform centre, strong process of cooperation and almost absent competition in structure. The given model is more characteristic for the heavy industry (large business). It is necessary to notice that the similar kind cluster differs, first of all, level of independence and economic interest in creation, and secondly, availability of innovative bases of functioning without which today there can not be no of subjects of system of business.

Taking into account all aforesaid it is possible to formulate general model of cluster region structures (picture 1).

\begin{tabular}{|c|c|c|c|c|}
\hline \multicolumn{5}{|c|}{ Public authorities } \\
\hline \multicolumn{5}{|c|}{ Cluster structure of region } \\
\hline \multirow{4}{*}{ 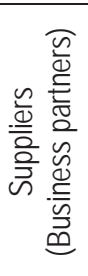 } & \multirow{4}{*}{$\begin{array}{ll}\text { Serving objects: } \\
-\quad \text { The service and repair centres; } \\
-\quad \text { The centres of sale of finished } \\
\quad \text { goods; } \\
-\quad \text { Building and transport } \\
\quad \text { structures; } \\
-\quad \text { Financial structures }\end{array}$} & The central element of cluster: industrial & \multirow{4}{*}{$\begin{array}{l}\text { Auxiliary objects: } \\
\text { - } \quad \text { The consulting; } \\
\text { - } \quad \text { The legal; } \\
\text { - } \quad \text { The leasing; } \\
\text { - } \quad \text { The factoring; } \\
\text { - } \quad \text { The insurance; } \\
\text { - } \quad \text { The investment. }\end{array}$} & \multirow{4}{*}{ 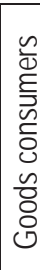 } \\
\hline & & the enterprise with regional specialisation & & \\
\hline & & Coordination council & & \\
\hline & & $\begin{array}{l}\text { Supplementing objects of cluster: The } \\
\text { research centers and laboratories, } \\
\text { educational institutions, techno parks, } \\
\text { business incubators }\end{array}$ & & \\
\hline \multicolumn{5}{|c|}{ Labour resource of region } \\
\hline
\end{tabular}

Picture 1. Model of cluster structures in Mary El Republics

For successful realisation system of cluster strategy of development of region and strategy of development separate clusters should be mutually agreed. It is a question not so much that necessity of development specified cluster should be registered in strategy and the industrial policy of region, and that there should be a consensus between the business and administrative elite of region directed on necessity of development clusters. Thus roles which should play the power and business at development clusters different, but always the complementary. The cluster approach originally used in researches of problems of competitiveness, should be used at the decision more and more a wide range of tasks, in particular:

- At the analysis of competitiveness of region, industry, the process enterprise;

- As a basis of a regional industrial policy;

- At development of programs of regional development;

- As a stimulation basis it is innovative-investment activity;

- As a basis of interaction big and a small business in the uniform social and economic integrated space.

\section{Method}

Integration, as well as realisation of functions, accordingly and the contribution and synergetic effect from activity of the enterprises cluster is performed, first of all, at level of municipalities - territories of presence of the enterprises. Therefore the most significant, separate levels (stages) of algorithm of cluster formation in region are:

- The analysis of potential of the future development cluster;

- Construction of the organizational-economic mechanism of interaction of subjects of different character within the limits of allocated cluster;

- An estimation of social and economic efficiency of functioning cluster.

The given levels are performed through a prism of city development and region strategy. The interrelation between program documents and the creation project cluster will be efficiency pledge of cluster formation at region level.

Change of models of managing and orientation with is innovative-investment economy put before region a problem of an intensification of economic growth by means of economic, social and institutional transformations of a social production. In these conditions the special importance is acquired by the applied innovative technologies focused on support key «growth points». Such «growth points» become clusters which being allocated on region territory provide uniform and balanced development of its economic actors (Popova, 2012). 
Forming and functioning process clusters not only promotes economic growth, but also transforms existing economic space of the regional subject in various formats, providing with that qualitative transition from raw to innovative model of managing.

\section{Results and Discussion}

In the concept of strategy of social and economic development of Republic Mary El till 2020 the organisation and activization of cluster formations is positioned as one of the major directions of creation of national system of support of innovations and the technological development, initiated by the regional centre.

The estimation technique is developed for determination of measures of administrative influence on elements, and processes of regional economy cluster potential of region which includes three stages.

At the first stage it is performed the descriptive analysis (includes descriptive representation of separate variables) and the comparative-historical analysis («the description and an explanation of similarities and distinctions (mainly distinctions) conditions or results of development of large social units, it is usual - regions, the countries, societies and cultures») statistical and analytical materials for a certain time horizon for level revealing cluster potential (Maslov, 2010).

On the second - synthesis of private (base) indicators in a uniform integrated indicator, ranging of regions and representation of results in the form of the standardised (rating) estimations is conducted.

At the third stage positioning of regions on a state of art cluster potential on the two-dimensional card is produced.

The estimation of cluster structures on an example of regions of Privolzhsky federal district has allowed to reveal groups of subjects with high, average, moderated and low levels of cluster potential of regional economic system that has predetermined a choice of measures of development cluster potential in a context of each group.

The effective model of management of forming and development cluster formations provides consecutive realisation of three stages: planning, creation and development. At a planning stage the purposes and tasks cluster are determined; it is analyzed cluster potential of region and competitiveness of cluster formation industries; the kind allocated cluster for the purpose of a choice of a correct path of its development is proved. Within the limits of the second stage the railroad train of participants cluster is determined; the management mechanism of cluster is formed by formation; measures of the state support get out and proved. At a development stage the estimation of efficiency of activity cluster is produced; correcting measures are developed and applied. Reasonable entering of function of the control which will allow to reveal in due time failures in development cluster structures in our opinion is and to make in due time adjustments necessary changes (Agalarov, 2012).

In territory of Republic of Mary El processes of cluster transformations pass on inertial and dirigisme to scenarios (dirigism is a policy of active intervention in management of economy from the state) that is in turn connected with accounting of some the factors interfering forming and development cluster. It is possible to carry to such factors as uncertainty of results, long duration of forming, low efficiency.

The offered liberal scenario provides restriction of a role of the state and includes: motivation, coordination and consolidation of participants cluster; assistance in simplification of legislative adjustment; creation focused on cluster zones of free trade, development of business incubators, industrial parks (techno parks) and parks of suppliers; development of objects of an infrastructure (transport, communication, consulting, etc.); the organisation of system of information support between subjects cluster that forms an innovative vector of development of economic system of region (Shchetinina, 2012).

It is necessary to notice that under cluster structures it is understood set of conditions, resources and the factors necessary for forming and effective functioning cluster of structures, providing competitive, steady and safe social and economic development of region.

For the purpose of realisation of procedure of monitoring cluster structures the conceptually-logic scheme of forming and development cluster the region potential, leaning on two base elements is developed: the block of factors of forming and the block of factors of readiness of use cluster potential in region (picture 2). 


\begin{tabular}{|c|c|c|c|c|c|}
\hline \multicolumn{6}{|c|}{$\begin{array}{l}\text { Level A - macro-condition of system } \\
\text { Cluster structure of potential of region }\end{array}$} \\
\hline \multicolumn{6}{|c|}{ Level B- meso-condition of system } \\
\hline \multicolumn{3}{|c|}{$\begin{array}{l}\text { Factors of possibility of forming cluster structures of potential of } \\
\text { region }\end{array}$} & \multicolumn{3}{|c|}{$\begin{array}{l}\begin{array}{l}\text { Factors of readiness of use cluster structures of potential of } \\
\text { region }\end{array} \\
\end{array}$} \\
\hline \multicolumn{6}{|c|}{ Component } \\
\hline 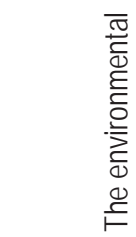 & 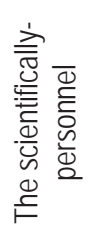 & 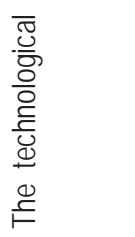 & 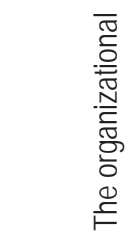 & 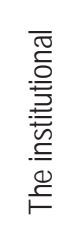 & 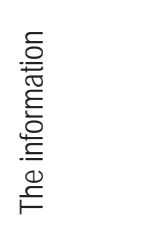 \\
\hline \multicolumn{6}{|c|}{ Level C - micro condition of system } \\
\hline
\end{tabular}

Picture 2. The structurally-logic scheme forming and developments cluster structures of regional economic system

On the basis of accounting of structural features cluster structures region, the technique of its estimation including analysis stages, rangings and positioning of region is developed and allowing to specify set, sequence and character of administrative influences on processes of clusterization of regional economic system. The complex technique is approved by carrying out of a multifactorial estimation of a state of art cluster structures on an example of regions of the Volga region from 2013 for 2014.

The basic direction of enhancement of management of social and economic development of region is based on use basis cluster technologies.

Table 1. Organizational model of management of forming cluster region formations

\begin{tabular}{|c|c|c|}
\hline $\begin{array}{l}\text { Competence and } \\
\text { responsibility level }\end{array}$ & Stages of cluster formations & Events \\
\hline \multicolumn{3}{|c|}{ I stage of planning cluster } \\
\hline Power state structures & 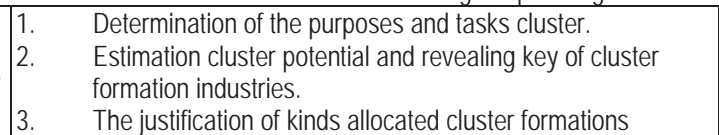 & $\begin{array}{ll}- & \text { Estimation cluster potential; } \\
- & \text { Estimation of competitiveness of industries; } \\
- & \text { Concept development cluster }\end{array}$ \\
\hline \multicolumn{3}{|c|}{ II stage of creation cluster } \\
\hline $\begin{array}{l}\text { Institute of cluster } \\
\text { management }\end{array}$ & \begin{tabular}{|ll} 
1. & Determination of a railroad train of participants cluster \\
2. & Motivation of participants and forming of working group \\
3. & Forming of the mechanism of management cluster formation \\
4. & Choice, the justification and application of measures on \\
& $\begin{array}{l}\text { realisation cluster politicians, including measures of the state } \\
\text { support }\end{array}$
\end{tabular} & $\begin{array}{l}\text { Assistance of realisation of measures on creation cluster: } \\
-\quad \text { The organizational help in coordination of efforts of } \\
\text { participants cluster; } \\
\text { - The organisation of meetings, forums, conferences }\end{array}$ \\
\hline \multicolumn{3}{|c|}{\begin{tabular}{|l|l} 
III stage of development cluster \\
\end{tabular}} \\
\hline $\begin{array}{l}\text { Institute of cluster } \\
\text { management }\end{array}$ & $\begin{array}{l}\text { 1. The Estimation of efficiency of activity cluster } \\
\text { 2. Development and application of correcting measures }\end{array}$ & $\begin{array}{l}- \\
\text { - } \\
\text { cystem engineering of indicators of development } \\
\text { analysis; } \\
\text { - } \\
\text { Efficiency estimation cluster as a whole and for its } \\
\text { separate participants }\end{array}$ \\
\hline
\end{tabular}

Effective process of forming and development cluster structures should combine in a complex elements both artificial, and natural methods of cluster formation. And in the conditions of the Russian validity there should be a state position, influence, responsibility and which competence should be maximum at a preparation stage, are partially delegated at a stage of realisation and essentially decrease at a development stage (table1).

In spite of the fact that such competitive industries are concentrated to territory of Republic of Mary El as industrial, agricultural, building, etc., process of their clusterization proceeds under the inertial scenario which prominent feature is latency, uncertainty and long duration. Regional authorities make active discrete processes cluster transformations of economy of region in industries of pharmaceutics, light industry and information-communication technologies. Pharmaceutical and textile clusters, being at a forming stage, are formed in a context of dirigisme the development scenario which is understood as concentration of economic, political, organizational and administrative resources by 
authorities for the purpose of forming and development cluster in region. The inefficient decisions accepted in the course of initiation textile cluster that has considerably lowered rates of its development became result of similar use cluster technologies. The greatest efficiency the liberal scenario in which the state role aside creation of innovative economic system is reviewed and which includes measures on motivation, coordination and consolidation of participants cluster possesses; to assistance in legislative guideline simplification; to creation focused on cluster zones of free trade, business incubators, industrial parks (techno parks) and parks of suppliers; to development of objects of an infrastructure (transport, communication, etc.); the organisations of system of information support between elements cluster development of cluster formations (Kanov \& Gasanov, 2012).

At the analysis cluster structures it is the most reasonable to allocate following characteristic properties which should be inherent in all clusters and distinguishing each of them from other economic consolidations. The following concerns them:

- Availability of a central business direction (kernels cluster) in which all elements of cluster structures unite and determine its strategic development;

- Nationalisation of resources by means of what all participants of cluster structures should have equal access to the limited resources in occupied territory (environmental, labour, scientific and technical, information, educational, etc.). For them the input threshold in cluster should be lowered, but the competition in cluster for resources is stronger, than in the open market that in turn determines the big propensity to risk and introduction of innovations in cluster;

- Structurization of consumers which in turn should differentiate internal consumption, export for limits cluster, export;

- Dynamism of cluster structures forms a free admission for participation in cluster, mobility of cluster structures, plural communications in cluster, informal dialogue and an exchange of experience, knowledge and technologies;

- Centripetal forces in cluster, forcing to co-operate with the enterprises-competitors, higher propensity to innovations, a classified risk of business and high return on laid-down capital - all it allows to develop cluster structures as the integrated structures with difficult intersubjective communications, as certain sort system objects.

In any cluster to structure business processes on transformation of various resources on an input in cluster, in material and not material benefits for the consumer on an exit necessarily proceed. Besides, processes in cluster to system at top level act in the aggregated form, generalising all integrated flows of all participants cluster, without dependence from a process accessory to the given participant. The information on the owner of process becomes actual only at the further steps of detailed elaboration (decomposition) of process (Kutsenko \& Meissner, 2013).

The process approach at modelling cluster relations in the theoretical plan shows process of the expanded reproduction at level of a regional economy. Process of the expanded reproduction of material benefits, labour, relations of production in cluster determines the economic processes proceeding in cluster the basic laws to which can be carried such as, advancing growth of production of means of production over consumption, the home market expansion, a growing competition in home market and demand for investments and innovations. The mechanism of the expanded reproduction in cluster underlines an urgency of application of the process approach for modelling cluster mechanisms owing to following reasons:

- The structure of a cumulative public product in cluster is represented at the process approach in functional proportions between divisions (links) of processes, thus owing to specific properties of cluster (availability of supporting and related industries) manufacturers of means of production represent itself as consumers of goods of other divisions, forming thus feedback, characteristic for dynamic systems;

- Owing to availability and possibility of nationalisation of resources in cluster (human, information, intellectual, natural, production etc.) there is a possibility of capital accumulation and realisation of the expanded reproduction without additional costs;

- On the basis of the analysis of structure of a cumulative public product in cluster and decomposition of processes on functional links there is possible a carrying out of the is functional-cost analysis for revealing of relationships of cause and effect in cluster, structures of potential and development prospects cluster structures. 


\section{Conclusion}

The analysis of conditions of forming cluster structures in Mary El Republic is conducted on motive forces in a cut of industries of economy of region. The analysis includes an estimation of motive forces on industries of economy of region, the analysis of dynamics of their development, and also intra-branch comparison on motive forces. Research is based on official historical data about economic development of region for 2013-2014. During the analysis of conditions of forming cluster structures in Mary El Republic four preconditions of research have been formulated (Kreneva S.G, Halturina E.N., Nurmuhametov I.M., Bakhtina T.B., 2015)

1. Forming only intra-branch clusters is researched. The official statistics contains the information subject to conditions, promoting occurrence clusters, only in a cut of industries of economy. Absence of statistics on intra-branch conditions of forming clusters does not allow to research the precondition for forming intra-branch clusters.

2. The supporting motive power is excluded from the analysis in connection with absence of statistics which characterise it in a cut of industries. It is necessary to notice that such exception does not render essential influence on results of intra-branch comparison as the given motive power is slightly differentiated on industries from the point of view of forming conditions cluster structures.

3. It is supposed that motive forces do not render influence against each other and represent rather independent areas in space of conditions of forming clusters. Thus, kits of the indicators reflecting scientific, production and financial potential, are specific and independent factors of forming intra-branch cluster can be considered as completely.

4. Research is limited to an estimation of motive forces and does not include construction of a uniform complex estimation of conditions of forming clusters.

The basic industries of republic are: the electric power industry, mechanical engineering and metal working, wood, wood- pulp \& paper industry, food and fuel industry, their cumulative share in industrial output constitutes $79,8 \%$.

The largest enterprises of republic are JSCo «Mari pulp-and-paper industrial complex», JSC0 «Krasnogorsky industrial complex of motor vans», JSCo «Factory of semi-conductor devices», LLC "Argus-Volga", LLC «Firm the Souvenir», Joint-Stock Company «Mari factory of a lime brick», JSCo «Krasnogorsky factory "Electric motor", JSCo "Mriholodmash ", JSCo "Marbiofarm", JSCo NP «Factory of artificial skin», JSCo "Volga pulp-and-paper industrial complex».

The main industrial centers - the city loshkar-Ola, the city Volzhsk, the city Kozmodemjansk, the city Zvenigovo.

Leading industry of agriculture - animal industries (dairy and meat \& diary cattle breeding, pig breeding, sheep breeding, poultry farming). In plant growing is a cultivation of grain crops (barley, oats, a rye, wheat) and forage crops, production of flax-dolguntsa, hop, vegetables, a potato.

In republic territory are successfully implemented a significant amount of investment projects in agriculture and in system of processing of agricultural goods. The largest investment project-it the project on agro holding "Alashevo" development where the sixth and seventh turns of development of the enterprise during the current year are finished and proceeds realisation of the investment project on building of the eighth turn of a poultry-farming complex in republic territory.

For the purpose of development in republic of industry of information technology, constructions of a complex infrastructure for the accelerated growth of the innovative IT companies which are engaged in development of the software and rendering of services in sphere of information-communication technologies, creation possibility in the IT park city loshkar-Ola is considered.

Within 2015 creation of investment platforms with an infrastructure and complex development of territories for placing of new productions will be continued. Today we can already offer investors ready investment platforms in formed Southern industrial a district of the city loshkar-Ola and in republic areas. Also it is accepted the decision on creation of industrial park "Southern" in territory of Southern industrial region the area not less than 20 thousand in sq. $\mathrm{m}$ where the production premises completely prepared for operation with all brought infrastructure will be given to investors. Now the concept of development of industrial park is confirmed and the plan of prime events for its creation is developed.

In total on territories of the Southern industrial region, which area constitutes 150 hectares, about 30 ground areas of the various area are planned to generate. The southern industrial region has a convenient geographical arrangement affinity to automobile and iron roads and has a necessary engineering infrastructure that does perspective realisation in its territory of projects and considerably reduces costs of investors to preparation and the design documentation coordination.

In the long term in territory of republic with participation of private investors creation and development touristic- 
recreational clusters "Tsar-hailstones" in loshkar Ola and "Volgydo" in Zvenigovsky and Gornomarijsky areas and the city Kozmodemjansk is provided. The specified projects are included in the list of events of the federal program «Development of internal and entrance tourism in the Russian Federation» with total amount of the investments involved within the limits of creation clusters, at a rate of more 4 billion roubles.

Today a number of projects already is implemented and planned for republic territories to realisation on development of internal and entrance tourism and creation of an infrastructure necessary for it. Among such projects it is possible to note creation of Mari tourist village "Vizimbir" in Kuzhenersky area, an eco-tourist complex "Chodyrajal" in Volzhsk area, tourist complexes "Volgavita", "Village fence" and «a nest Of noble family» in Kilemarsky area and as a whole development in republic cultural-informative, sports, trade, extreme, educational and other kinds of tourism.

In Mary El Republic in 2014 in comparison with 2013 high rates of increase of indicators in the basic industries of economy and increase of a standard of living of the population are provided:

- The industrial production index has increased on $13,6 \%$;

- The volume of agricultural goods has grown on $15,8 \%$;

- Turnover of retail trade has increased on $5,4 \%$;

- Commissioning of apartment houses has increased by $12,4 \%$;

- Per capita monetary incomes of the population have increased on 12,2\% and have constituted 16287,8 roubles, including for December, 2014 - 22 210,2 roubles;

- The monthly average salary has increased by $12,3 \%$ and has constituted 20414,6 roubles, including for December, 2014 - 26 699,5 roubles.

On development of economy and social sphere of republic for 2014 it is directed investments into fixed capital into the sum of 48,4 billion roubles that is more than level of 2013 on 3,2 billion roubles.

On rates of increase industrial and agricultural production Mary El Republic among regions of Privolzhsky federal district for 2014 left on 1 place. Mary El has large stocks of a building stone, keramzit raw, brick-tile raw, carbon breeds for liming of soils, a stone facing, peat, sapropel, mineral waters and a dirt. Investigation of other minerals is led. The basic natural riches of Republic of Mary El is wood, the total area of wood fund constitutes more than 1200 thousand in hectare or $57 \%$ of territory of republic.

Historical data on Mary El Republic during the last years allow to allocate industries which are large independent sectors of economy of region in which can be formed clusters:

- Agriculture;

- Mining operations;

- The food-processing industry;

- Clothes and footwear production;

- Woodworking;

- Pulp-and-paper production;

- Chemical production;

- Mechanical engineering;

- The electro technical industry;

- The transport industry;

- Power and water supply;

- Building industry;

- Hotels and restaurants;

- Transport and communication;

- Financial activity;

- Operations with a real property, rent and granting of services;

- Education;

- A health care and social services.

The analysis of the accessible statistical information has allowed to specify the indicators which are most objectively reflecting conditions of forming cluster of structures in industries of economy to Republic of Mary El on motive forces.

Indicators of scientific force:

- A state of art of research base of industry;

- A state of art of university system in the given industry;

- A share of the enterprises of industry which perform innovations; 
- A share of employees of the enterprises of the industry which are engaged R\&D.

- Indicators of production force:

- Investments into fixed capital;

- Quantity of the workers occupied in industry;

- Level of a monthly average salary in industry.

- Indicators of financial force:

- consolidated financial result of the enterprises of industry;

- Average profitability of turnover of the enterprises of industry;

- Relative density of the unprofitable enterprises in the given industry.

Lately Russia is accompanied by constant economic sanctions from the West and the forced protective measures from our party. Mary El republic has faced necessity of forming new industrial and an agrarian policy which should provide break in production efficiency increase.

Despite West sanctions in Mary El Republic growth of industrial production, agriculture and building goods is noted. For January-March, 2015 rate of increase of a total regional product has constituted 101,9\%, an index of industrial production of $125,2 \%$ (the similar period of $2014-98,2 \%$ ). Following the results of three months the indicator on industry has constituted $126,5 \%$. For the comparison, the corresponding period of 2014 on the given line of activity has been noted by growth of $17,4 \%$.

The plan of prime events for provision of a sustainable development of economic system and social stability is developed for decrease in negative influence of the crisis phenomena in republic. Besides, among priorities there are questions import substitution that opens new prospects for development of local commodity producers in various industries.

Increase of competitiveness of a domestic production is one of the most difficult and pressing questions of today. It is necessary, that all questions found the decision at level of the Russian regions since here there is a direct embodiment in life of planned projects. Realisation of cluster structures will allow to strengthen positions of the regional enterprises both on internal, and in a foreign market, will promote escalating of their potential on production of competitive goods and saturation of the commodity and consumer markets by qualitative domestic agricultural goods.

\section{Acknowledgements}

The author expresses deep gratitude to reviewers for detailed consideration of the manuscript and valuable remarks.

\section{References}

Agalarov, E.G. (2012). Cluster approach as a tool for sustainable development of rural areas. Young scientist. № 4. 92-95 p.

Kanov, V.I., Gasanov, M.A. (2013). The cluster as a structural economic competitiveness Institute. Bulletin of Tomsk State University. № 34 (24), 97-103 p.

Kozlikina, Y.A. (2014). Regional innovation clusters as a tool for improving the competitiveness of the territories. Economic science and practice: Materials III Intern. scientific. Conference. 159-161 p.

Kreneva, S.G, Halturina, E.N., Nurmuhametov, I.M., Bakhtina, T.B. (2015). / Formation the Model of Criterial Indicators of Resource Potential of Small and Average Business Subjects of Mary El Republic. Review of European Studies, Vol. 7, No. 8, 270 p.

Kutsenko, E. S., Meissner, D. (2013). Key Features of the First Phase of the National Cluster Programme in Russia. Technology and Innovation. WP BRP. Higher School of Economics, 11.

Malitskaya, E.A., Volkov, V.I. (2012). Cluster-oriented regional policy as a tool to improve the competitiveness and innovative activity of regions. Municipality. № 4. 10-14 pages.

Maslov, V. P. (2010). New critical points for the liquid phase and the construction of the rmodynamics depending on the interaction potential. Mathematical notes. 5, 723-731 p.

Popova, M.V. (2012). Foreign experience of cluster policy for the development of regional competitiveness. Theoretical and applied problems of science and education in the 21st century. Collection of scientific papers based on the correspondence of the International scientific and practical conference. № 5. 112-114p.

Shchetinina, N.Y. (2012). Competitive technology clusters. Creative Economy. № 12 (72), 72-80 p.

Skubko, A.V. (2010). Methodological approaches to assessing the competitiveness of the Russian economy. Proceedings of Institute of Economic Forecasting. № 4, 617-626 p. 